\title{
The acceptability of cervical electrical impedance spectroscopy: A mixed methods study examining women's experiences of a novel test to predict preterm birth
}

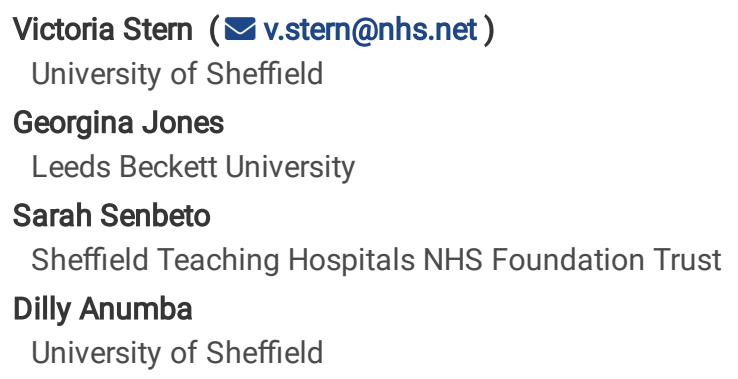

Keywords: Electrical Impedance Spectroscopy, Cervix, Screening, Preterm Birth, Preterm labour, Acceptability, Maternal Experience, Mixed Methods, Triangulation

Posted Date: June 7th, 2022

DOI: https://doi.org/10.21203/rs.3.rs-1339165/v2

License: (c) This work is licensed under a Creative Commons Attribution 4.0 International License. Read Full License 


\section{Abstract Background}

Reducing the rate of preterm birth is a cornerstone of global efforts to address child mortality. Existing tests offer imperfect prediction, particularly for universal screening. Cervical electrical impedance spectroscopy (EIS) is a novel technique to quantify the ripening changes which precede labour. Mid-trimester EIS measurements have been shown to accurately predict preterm birth in asymptomatic women. This study aimed to comprehensively evaluate the acceptability of cervical EIS to low and high-risk women undergoing screening during a larger prospective trial.

\section{Methods}

In this parallel convergent mixed methods study, 40 women completed questionnaires before and after screening tests (EIS, cervical length measurement and fetal fibronectin quantification). Quantitative outcomes were anxiety levels before and after screening (Spielberger State Trait Anxiety Inventory, STAI-6), pain (Short Form McGill Pain Questionnaire) and ratings of EIS device appearance and test acceptability (visual analogue scales). Twenty-one women (11 high-risk, 10 low-risk) also attended a semi-structured qualitative interview. Interviews were recorded and transcribed, then thematic analysis was performed. A convergence coding matrix was constructed to enable triangulation of quantitative and qualitative results.

\section{Results}

High risk women demonstrated a significant reduction in anxiety following screening (mean STAl-6 score 34.5 vs. 29.0, $p=0.002$ ). A similar trend was observed among low-risk participants. Ratings of pain, ElS device appearance and procedural acceptability did not differ between groups. Mean pain ratings were low (visual analogue scale 0.97 and 1.01), comparing favourably to published evaluations of conventional screening tests. Qualitative analysis provided insight into both the physical consequences and emotional experiences of screening. Additional determinants of the screening experience included device design, pre-existing perspectives on intimate examination, attitudes to knowledge in pregnancy and interaction with clinical staff. Finally, a range of practical considerations regarding wider use of EIS were identified, with valuable complementary detail regarding acceptability for use in antenatal care.

\section{Conclusions}

Cervical EIS is well tolerated and acceptable to both low and high-risk women. These results provide useful insights to inform the design of future study and screening protocols

\section{Background}

Worldwide, preterm birth (PTB) is the leading cause of neonatal mortality ${ }^{1,2}$ with significant long-term morbidity amongst survivors ${ }^{2}$. Prediction and prevention of PTB have repeatedly been identified as key to improving obstetric outcomes ${ }^{3,4}$. However, the PTB syndrome has diverse aetiologies ${ }^{5}$ thus calculating which women will deliver early is challenging. Increasingly global, including UK, guidance recommends that women with prior PTB or late miscarriage undergo transvaginal ultrasound (TVUSS) measurement of cervical length (CL) ${ }^{6}$. Other commentators advocate the addition of quantitative vaginal fetal fibronectin (FFN) estimation in high-risk asymptomatic women. However, both tests have relatively poor predictive performance when applied to an unselected or low risk population 7,8 , and effective universal screening tests prove elusive. The ideal screening programme would offer good predictive accuracy for both high and low risk groups as nulliparous women, in particular, are not well served by existing risk-factor based approaches.

The cervix represents the "final common pathway" in the process of preterm parturition ${ }^{5}$ - it must remodel and dilate for PTB to occur, regardless of the initial trigger. It is therefore a logical target for PTB screening. Electrical impedance spectroscopy (EIS) is a technique with proven ability to interrogate tissue structure ${ }^{9-12}$, originally used in the detection of pre-malignant changes within the cervix ${ }^{9}$. A recent prospective study of asymptomatic women confirmed that mid-gestation cervical EIS measurements can accurately predict spontaneous PTB before 37 weeks ${ }^{13}$ and has potential for incorporation into existing risk prediction algorithms ${ }^{14}$. It is plausible that using a multi-modal package of screening tests might optimise PTB prediction and enhance predictive accuracy in both low and high risk groups. Further studies are necessary to confirm the benefit of incorporating EIS into existing screening protocols, but it is also essential to confirm that it is acceptable to pregnant women. We therefore conducted a parallel convergent, mixed methods study to systematically evaluate the acceptability of EIS to women at both high and low risk of preterm birth. This sub-study was nested within a larger prospective trial examining the predictive accuracy of EIS ${ }^{13}$. 
No previous research has examined patients' experiences of undergoing EIS measurements. Furthermore, the literature regarding women's perspectives on PTB screening is relatively sparse. Studies are predominantly quantitative, with questionnaires employed to examine factors such as pain, anxiety, and embarrassment during CL scans ${ }^{15-19}$ and anxiety associated with FFN testing ${ }^{18,20}$. More recently, the impact of the Quantitative Instrument for the Prediction of Preterm Birth application (QUiPP app) (which combines obstetric history, CL and FFN to estimate PTB risk) has also been assessed via questionnaire 21 .

Five qualitative studies have considered screening as a factor in the experiences of women at risk of PTB; these have studied high-risk asymptomatic women ${ }^{22}$, those with symptoms of preterm labour ${ }^{23,24,25}$ or a mixture of the two ${ }^{26}$. All employed semi-structured interviews either individually or via focus groups. Three focused on women's experiences of antenatal care, via PTB clinic attendance 22 or during symptomatic presentations ${ }^{23,24}$. Two specifically examined women's decision-making during episodes of threatened preterm labour 25,26 .

No research has been identified which uses mixed methods to synthesize both quantitative and qualitative data. Such a technique can be advantageous in providing a comprehensive view of patient experience. Furthermore, triangulation of quantitative and qualitative datasets may enhance validity, allowing areas of convergence, dissonance and silence to be highlighted ${ }^{27,28}$. We therefore aimed to employ validated quantitative measures of pain and anxiety to examine women's experiences of EIS (allowing comparison to existing PTB screening literature) but also to conduct semi-structured qualitative interviews to obtain greater detail regarding women's EIS and PTB screening experiences in general (to enhance and explain our quantitative findings).

\section{Methods}

Ethical approval for this study was provided by the Yorkshire and Humber National Research Service Ethics Committee (13/YH/0167).

\section{Setting}

Women received verbal and written information about the main EIS study during booking appointments at the Jessop Wing, Sheffield (a large teaching hospital). They were eligible for inclusion if aged over sixteen, with good comprehension of English and were carrying a singleton pregnancy, with no evidence of fetal anomaly. Non-English speakers, women with multiple pregnancies or those with factors which precluded accurate EIS measurements (recent abnormal smear test, active cervical infection or bleeding) were excluded. Low-risk women (LRW) were primiparous or multiparous with no risk factors for PTB. High-risk women (HRW) had a history of one or more previous PTB and/or late miscarriages. If interested, they were later contacted to confirm recruitment. LRW attended one research visit at 20-22 weeks, HRW again at 2628 weeks.

At the main research visit women underwent a series of tests: an initial speculum examination (when swabs were taken for infection screening and FFN quantification, then EIS measurements were obtained) followed by a CL scan. Women received results of the CL scan immediately and no information regarding their EIS measurement (all were informed it would not be possible to interpret EIS results during the study). Women either received their FFN result during the research appointment or were contacted shortly afterwards. Appropriate follow up was arranged for those with abnormal results. All results were explained and treatment arranged if necessary. The same clinician (VS) conducted all study visits.

\section{Data collection}

Before the first study visit, forty women were also invited to participate in the acceptability study. This group was identified via purposive convenience sampling over 12 months spanning the mid-point of recruitment to the clinical trial (November 2014 to October 2015) - this ensured the study procedures were well embedded and operator experience with the EIS probe was high. Those expressing interest completed two questionnaires: a short pre-visit anxiety rating (administered immediately before the three predictive tests) and a longer post-visit questionnaire (administered at the end of the study visit once all tests had been performed). Introductory text explained that the specific purpose of the questions was to assess the acceptability of EIS. Discrimination of the timing of EIS measurements was possible due to both the sensation of contact with the cervix and due to the 'beeping' noise made by the EIS probe during clinical measurement. After expression of interest, women were later contacted by a research midwife to confirm participation in the interview stage. Twenty-one women consented and attended an interview. Once recruitment to the interview phase was complete, no further questionnaire data was collected. Where possible, interviews were arranged within four weeks of the main study visit. They were conducted by a research midwife (SS) with training and experience of qualitative interviewing. The use of purposive sampling aimed to ensure a balance of low and high-risk participants, with a range of ages, ethnicities, socio-economic statuses and varied obstetric histories. Recruitment to interview continued until saturation of themes was achieved.

Mixed methods research encompasses a broad range of study designs, but typically incorporates both quantitative and qualitative methodologies. However, each aspect may be afforded different priority and methods may be performed in sequence or concurrently, depending 
on the desired outcome $\mathrm{e}^{28}$. Our convergent parallel design aimed to afford equal weight to both datasets, with the intention of producing an integrated summary which captured the strengths of both quantitative and qualitative approaches.

\section{Quantitative data collection}

The pre and post-visit questionnaires were designed to assess women's anxiety before and after tests; any pain experienced during EIS measurements; women's views of the probe design and overall acceptability of the EIS test. In order to assess anxiety, the six-question short form of the Spielberger State-Trait Anxiety Inventory (STAI-6) was used ${ }^{29}$. This abbreviated version of the full, forty-question STAI has been validated for use in the perinatal period and has high internal consistency and reliability ${ }^{30}$. Given the potential association between maternal stress and preterm birth ${ }^{31}$, it was important to evaluate whether undergoing EIS measurements adversely affected anxiety levels.

Pain during EIS measurement was assessed using the short form of the McGill pain questionnaire. This provides a multidimensional measure of pain which has previously been validated in obstetric patients ${ }^{32}$. It includes two measures of pain intensity: the visual analogue scale (VAS) and the Present Pain Intensity (PPI) plus a Pain Rating Index (PRI) designed to assess the qualities of any pain experienced. Finally, women rated their perception of the appearance of the EIS device and the overall acceptability of the procedure using a ten-point VAS. They were asked to proffer their recommended changes to the testing procedure and the potential acceptability of the procedure for use in routine antenatal care. The ten-point VAS is widely used and validated for the assessment of pain ${ }^{33,34}$ but has also been employed and validated more broadly to evaluate $\operatorname{mood}^{35,36}$ and valuation of other health states ${ }^{37}$.

\section{Qualitative data collection}

The semi-structured interview schedule (Additional file 1) was designed collaboratively by the interdisciplinary research team (VS, SS, GJ and DA). It consisted of nine open and two closed questions designed to elicit women's experiences of attending the visit and undergoing tests. The schedule provided a guide, however the interviewer varied the order and structure of the questions as she deemed appropriate, and followed other lines of enquiry if topics of interest arose. Use of a semi-structured approach enabled key objectives to be achieved (obtaining a detailed account of women's experiences of the tests) whilst allowing flexibility to explore themes which the women themselves might introduce.

The interviewer (SS) was not involved in the clinical care of the women. This neutrality was important to enable participants to reflect freely on their experience without inhibitions or fear of impacting their care. Women chose the location of their interview (at home or in the university research department) and two patients were interviewed during an inpatient antenatal admission (in private side rooms). Interviews lasted 30 minutes on average and were audiotaped and transcribed verbatim later. Participants provided separate written informed consent for the qualitative study.

\section{Data analysis}

Given the lack of prior studies of EIS acceptability, an exploratory, pragmatic approach, grounded in the lived experiences of our participants felt most appropriate. Pragmatism as a perspective focuses on the cyclical interaction of human beliefs and actions in shaping experience ${ }^{38}$. It enables a technical approach to be taken, in which methods are selected due to their ability to best answer a research question, rather than to fit in with a particular epistemological philosophy ${ }^{38,39}$ and navigates the tension potentially encountered when trying to combine what might otherwise be viewed as conflicting quantitative and qualitative methodologies.

Questionnaire data were analysed using the relevant scoring algorithms and descriptive statistics calculated. Mean pain scores (McGill VAS and PRI), mean anxiety scores before and after testing (STAI-6), mean change in STAI-6 scores, and mean acceptability and device design ratings (both VAS) for high and low risk groups were then compared. The proportion of high and low risk women with high anxiety scores were also compared as were 'within-group' pre and post visit scores. Normality of score distribution was assessed via the Shapiro-Wilk test. Mann Whitney $\mathrm{U}$ tests were performed to compare nonparametric data whilst independent and paired $\mathrm{T}$ tests were performed to compare normally distributed scores. Fisher's exact test was employed for the comparison of categorical outcomes. Data analysis was performed using SPSS (IBM Corp. Released 2017. IBM SPSS Statistics for Windows, Version 22.0. Armonk, NY: IBM Corp). Application of a Bonferroni correction yielded an adjusted alpha level of $0.005(0.05 / 10)$.

Qualitative analysis proceeded as follows: Interview transcripts were uploaded to NVivo 10 (QSR International: Burlington MA) and checked for accuracy (VS). The first three interviews (of two HRW and one LRW) were reviewed by three researchers (VS, GJ and SS). Inductive thematic analysis (TA) (following the five-step process described by Braun and Clarke ${ }^{40}$ ) was employed to develop an initial coding framework, which was continually reviewed during analysis of the remaining interviews. Briefly, this involved familiarisation with the data; generating initial codes; searching for themes; reviewing, defining and naming themes; and producing an overall synthesis, including detailed examples, to interpret and make sense of the data ${ }^{40}$. For the purposes of this study, which aimed to explore women's experiences of undergoing a novel screening test, the ability of TA to "describe the data set in rich detail" 40 and interpret identified patterns in the context of the overall research question was particularly apposite. 
Themes were inductively defined from the raw data through exploration without any predetermined classification where possible. A quarter of the interviews were coded by two researchers (VS and SS) to enable ongoing comparison and refinement of the coding structure, and potential themes were discussed amongst the research team as analysis progressed to maintain reflexivity. Whilst formal assessment of inter-coder reliability is not a pre-requisite for thematic analysis, this comparison of ideas and ongoing dialogue between members of the research team ensured a wide and inclusive approach and was maintained during initial coding.

Following analysis of the two datasets, a mixed methods matrix was constructed (summarising the results of participants with paired data). This enabled systematic comparison of qualitative and quantitative information, specifically looking for areas of convergence, dissonance, silence or complementarity within cases ${ }^{27}$. A convergence coding matrix was also constructed (similar to that advocated by Farmer et al. ${ }^{41}$ although generated by a single researcher, VS) to summarise the results of both study components and the triangulation process in a single location (Additional file 2). This enabled the overall questionnaire results to be synthesized with the SSI themes, in addition to the within-case triangulation generated by the matrix.

\section{Results}

\section{Quantitative survey}

Overall questionnaire results are summarised in Table 1.

Table 1

- Results of quantitative survey

\begin{tabular}{|c|c|c|c|c|}
\hline Survey Domain & & $\begin{array}{l}\text { High Risk } \\
\text { Women } \\
(n=20)\end{array}$ & $\begin{array}{l}\text { Low Risk } \\
\text { Women } \\
(n=20)\end{array}$ & $\begin{array}{l}\text { P value } \\
\text { (HR vs } L R \text { ) }\end{array}$ \\
\hline \multicolumn{5}{|l|}{ Anxiety } \\
\hline \multirow[t]{7}{*}{ STAI-6 results } & Mean pre-test score (SD) & $34.48(12.72)$ & $29.98(8.98)$ & 0.204 \\
\hline & Mean post-test score (SD) & $28.98(10.20)$ & $27.50(9.48)$ & 0.881 \\
\hline & $\mathrm{P}$ value pre $v s$. post test & 0.002 & 0.018 & \\
\hline & Mean difference & -5.55 & -3.22 & 0.628 \\
\hline & & $(-20$ to 0$)$ & $(-13$ to +27$)$ & \\
\hline & Pre-test score $\geq 39$ & $6 / 20(30 \%)$ & $4 / 20(20 \%)$ & 0.273 \\
\hline & Post-test score $\geq 39$ & $5 / 20(25 \%)$ & $2 / 20(10 \%)$ & 0.202 \\
\hline \multicolumn{5}{|l|}{ Pain/discomfort } \\
\hline SF-McGill VAS & Mean VAS score (range) & $0.97(0-3.2)$ & $1.01(0-3.1)$ & 0.935 \\
\hline \multirow[t]{3}{*}{ SF-McGill PPI } & $0-$ no pain & $7 / 20(35 \%)$ & $9 / 20(45 \%)$ & \\
\hline & 1 - mild pain & $11 / 20(55 \%)$ & $9 / 20(45 \%)$ & \\
\hline & 2 - discomforting & $2 / 20(10 \%)$ & $2 / 20(10 \%)$ & \\
\hline \multirow[t]{2}{*}{ SF-McGill PRI } & Mean Sensory PRI score (range) & $1.25(0-3)$ & $1.60(0-5)$ & 0.448 \\
\hline & Mean Affective PRI score (range) & $0.10(0-1)$ & $0.05(0-1)$ & 0.553 \\
\hline \multicolumn{5}{|c|}{ EIS probe design rating ( 0 = not threatening; $5=$ neutral; $10=$ very threatening $)$} \\
\hline & Mean VAS score (range) & $1.30(0-5)$ & $1.35(0-9)$ & 0.988 \\
\hline \multicolumn{5}{|c|}{ Acceptability rating ( 0 = acceptable; $5=$ neutral; $10=$ unacceptable) } \\
\hline Personal acceptability & Mean VAS score (range) & $0.55(0-3)$ & $0.75(0-5)$ & 0.842 \\
\hline \multirow[t]{2}{*}{ Acceptable for use in antenatal care? } & Yes & $20 / 20(100 \%)$ & $20 / 20(100 \%)$ & \\
\hline & No & $0 / 20(0 \%)$ & $0 / 20(0 \%)$ & \\
\hline
\end{tabular}




\section{Anxiety}

No significant differences in anxiety scores were observed between high and low risk groups at either timepoint. HRW showed a significant reduction in pre- $v$ s. post-test STAI- 6 scores; A similar trend was observed amongst LRW but did not reach significance $(p=0.002$ and 0.018 respectively, Mann Whitney $U$ ). There is no universally accepted threshold which defines the presence of significant anxiety, but it has been suggested that scores of $39-40$ represent a higher level ${ }^{42}$. When considering those with STAl scores $\geq 39$, higher anxiety levels were more prevalent amongst HRW at both time points. However, the incidence of scores $\geq 39$ was lower after screening regardless of risk status.

On an individual level, two women (10\% of the LR group) demonstrated higher scores after screening. Both were low risk participants - one experienced bleeding following examination and the other received abnormal test results. The remainder showed no change or a reduction in anxiety levels.

\section{Pain}

No significant differences in pain intensity experienced during EIS readings were observed between HRW and LRW. Average scores were low, with a mean VAS score of 0.97 for HR and 1.01 for LR participants ( $p=0.94$, Mann Whitney $U$ ), and a maximal score of 3.2 and 3.1 in each group respectively. When the ordinal PPI scores are considered, $90 \%$ of each group described either "no" or "mild" pain.

The results of the Pain Rating Index are summarised in Fig. 1, which displays the mean intensity rating for each qualitative descriptor in both sensory and affective domains, by study group. Women chose a broad range of descriptors, but the most commonly selected in both groups were "aching", "heavy" and "tender". However, it is notable that intensity ratings were almost exclusively 0 or 1 (no or mild pain), with only two scores of 2 (moderate pain) provided - one for the "tender" descriptor and the other for the "cramping" descriptor, by different low risk women. Affective descriptors were not commonly chosen by either group.

\section{Impression of EIS probe design}

$75 \%$ of participants rated the appearance of the EIS device as 1 or less (VAS), with no significant difference observed between risk groups. Figure 2 illustrates the design of the Mark $\mathrm{V}$ probe used during clinical study visits.

\section{Overall personal acceptability rating and perspective on use in wider antenatal care}

Having completed the anxiety, pain and device appearance ratings, participants were asked to appraise how acceptable they found the overall experience of undergoing EIS (via VAS) and whether they deemed it suitable for use antenatally. 100\% of participants agreed EIS measurements would be acceptable for future use in antenatal care (binary rating). Mean VAS ratings were similar between groups (0.55 HR (range $0-3)$ vs. 0.75 LRW (0-5), $\mathrm{p}=0.84$, where $0=$ acceptable, $5=$ neutral and $10=$ unacceptable).

\section{Qualitative analysis}

The characteristics of the women who participated in the semi-structured interviews are summarised in Table 2. There was a preponderance of white British participants, although this was representative of the main study cohort. Effort was nevertheless made to capture the views of different ethnic groups, with support from a clinically experienced translator in one case. Women of different ages, socio-economic statuses and with varied obstetric histories were interviewed to capture as diverse a range of experience as possible. Participants ranged in age from 19 to 38 years and spanned the full range of indices of multiple deprivation (IMD) with 43\% of participants residing in areas with IMD 1 to 5 and $57 \%$ with IMD 6 to 10. 76\% were White British, 4.7\% Black African, 4.7\% Arabic, 4.7\% South Asian, 4.7\% White European and 4.7\% White American. 
Table 2

- Characteristics of Qualitative Interview Participants

\begin{tabular}{|c|c|c|c|c|c|c|c|c|c|c|c|c|}
\hline $\begin{array}{l}\text { Pt } \\
\text { No. }\end{array}$ & $\begin{array}{l}\text { Location } \\
\text { of } \\
\text { interview }\end{array}$ & Age & Ethnicity & $\begin{array}{l}\text { Marital } \\
\text { staus }\end{array}$ & $\mathbf{G}$ & $\mathbf{P}$ & $\begin{array}{l}\text { Gestation of } \\
\text { previous } \\
\text { preterm birth } \\
\text { or } \\
\text { miscarriage }\end{array}$ & Group & $\begin{array}{l}\text { Having } \\
\text { serial } \\
\text { CL } \\
\text { scans } \\
\text { as } \\
\text { well? }\end{array}$ & $\begin{array}{l}\text { PTB } \\
\text { prophylaxis? }\end{array}$ & $\begin{array}{l}\text { Previous } \\
\text { speculum } \\
\text { exam? }\end{array}$ & $\begin{array}{l}\text { Index of } \\
\text { Multiple } \\
\text { Deprivation } \\
\text { (IMD) } \\
\text { Decile* }\end{array}$ \\
\hline 1 & Home & 25 & $\begin{array}{l}\text { White } \\
\text { European } \\
\text { (Polish) }\end{array}$ & $\begin{array}{l}\text { Co- } \\
\text { habiting }\end{array}$ & 2 & 1 & $n / a$ & $\begin{array}{l}\text { Low } \\
\text { risk }\end{array}$ & no & no & yes & 5 \\
\hline 2 & University & 33 & $\begin{array}{l}\text { White } \\
\text { British }\end{array}$ & Married & 5 & 0 & $\begin{array}{l}\text { Four 1st } \\
\text { trimester } \\
\text { miscarriages }\end{array}$ & $\begin{array}{l}\text { Low } \\
\text { risk }\end{array}$ & yes & no & yes & 10 \\
\hline 3 & University & 21 & $\begin{array}{l}\text { White } \\
\text { British }\end{array}$ & $\begin{array}{l}\text { Co- } \\
\text { habiting }\end{array}$ & 2 & 1 & $\mathrm{n} / \mathrm{a}$ & $\begin{array}{l}\text { Low } \\
\text { risk }\end{array}$ & no & no & yes & 7 \\
\hline 4 & University & 36 & $\begin{array}{l}\text { White } \\
\text { British }\end{array}$ & Married & 3 & 2 & $\begin{array}{l}\text { Term birth } \\
\text { then } 31 \text { week } \\
\text { delivery. }\end{array}$ & $\begin{array}{l}\text { High } \\
\text { risk }\end{array}$ & yes & no & yes & 9 \\
\hline 5 & University & 35 & $\begin{array}{l}\text { White } \\
\text { British }\end{array}$ & Married & 4 & 2 & $\begin{array}{l}\text { One } 30+ \\
\text { delivery } \\
\text { following } \\
\text { term birth }\end{array}$ & $\begin{array}{l}\text { High } \\
\text { risk }\end{array}$ & yes & no & yes & 6 \\
\hline 6 & University & 19 & $\begin{array}{l}\text { White } \\
\text { British }\end{array}$ & $\begin{array}{l}\text { Co- } \\
\text { habiting }\end{array}$ & 4 & 2 & $\begin{array}{l}\text { One } 36+0 \\
\text { delivery, term } \\
\text { birth since }\end{array}$ & $\begin{array}{l}\text { High } \\
\text { risk }\end{array}$ & no & no & yes & 7 \\
\hline 7 & University & 38 & $\begin{array}{l}\text { White } \\
\text { British }\end{array}$ & Married & 2 & 0 & $\begin{array}{l}\text { One 1st } \\
\text { trimester } \\
\text { miscarriage }\end{array}$ & $\begin{array}{l}\text { Low } \\
\text { risk }\end{array}$ & no & no & yes & 5 \\
\hline 8 & University & 28 & $\begin{array}{l}\text { Black } \\
\text { African }\end{array}$ & Single & 3 & 1 & $\mathrm{n} / \mathrm{a}$ & $\begin{array}{l}\text { Low } \\
\text { risk }\end{array}$ & no & no & yes & 1 \\
\hline 9 & University & 34 & $\begin{array}{l}\text { White } \\
\text { British }\end{array}$ & Married & 2 & 1 & $\mathrm{n} / \mathrm{a}$ & $\begin{array}{l}\text { Low } \\
\text { risk }\end{array}$ & yes & no & yes & 8 \\
\hline 10 & University & 29 & $\begin{array}{l}\text { White } \\
\text { British }\end{array}$ & Married & 1 & 0 & $\mathrm{n} / \mathrm{a}$ & $\begin{array}{l}\text { Low } \\
\text { risk }\end{array}$ & no & no & yes & 4 \\
\hline 11 & University & 33 & $\begin{array}{l}\text { White } \\
\text { American }\end{array}$ & Married & 3 & 2 & $\begin{array}{l}\text { One } 29+ \\
\text { delivery, term } \\
\text { birth since }\end{array}$ & $\begin{array}{l}\text { High } \\
\text { risk }\end{array}$ & yes & progesterone & yes & 5 \\
\hline 12 & University & 28 & $\begin{array}{l}\text { White } \\
\text { British }\end{array}$ & Married & 2 & 0 & $\begin{array}{l}\text { One } 23+ \\
\text { delivery and } \\
\text { neonatal } \\
\text { death }\end{array}$ & $\begin{array}{l}\text { High } \\
\text { risk }\end{array}$ & yes & $\begin{array}{l}\text { USS } \\
\text { indicated } \\
\text { suture }\end{array}$ & yes & 9 \\
\hline 13 & Home & 35 & $\begin{array}{l}\text { White } \\
\text { British }\end{array}$ & Married & 3 & 1 & $\mathrm{n} / \mathrm{a}$ & $\begin{array}{l}\text { Low } \\
\text { risk }\end{array}$ & no & no & yes & 10 \\
\hline 14 & University & 37 & $\begin{array}{l}\text { White } \\
\text { British }\end{array}$ & Married & 7 & 3 & $\begin{array}{l}\text { 1st trimester, } \\
14 / 40 \text { and } \\
20 / 40 \\
\text { miscarriage. } \\
2 \text { term births } \\
\text { before and } \\
\text { once since } \\
\text { miscarriages. }\end{array}$ & $\begin{array}{l}\text { High } \\
\text { risk }\end{array}$ & yes & no & yes & 1 \\
\hline 15 & University & 30 & $\begin{array}{l}\text { White } \\
\text { British }\end{array}$ & Married & 3 & 2 & $\begin{array}{l}\text { One } 35+5 \\
\text { delivery, term } \\
\text { birth since }\end{array}$ & $\begin{array}{l}\text { High } \\
\text { risk }\end{array}$ & no & no & yes & 10 \\
\hline 16 & University & 29 & Pakistani & Married & 3 & 2 & $\begin{array}{l}\text { One } 29+\text { one } \\
27 \text { week } \\
\text { delivery }\end{array}$ & $\begin{array}{l}\text { High } \\
\text { risk }\end{array}$ & yes & progesterone & yes & 1 \\
\hline 17 & Home & 33 & $\begin{array}{l}\text { White } \\
\text { British }\end{array}$ & Married & 1 & 0 & $\mathrm{n} / \mathrm{a}$ & $\begin{array}{l}\text { Low } \\
\text { risk }\end{array}$ & no & no & yes & 10 \\
\hline
\end{tabular}




\begin{tabular}{|c|c|c|c|c|c|c|c|c|c|c|c|c|}
\hline $\begin{array}{l}\text { Pt } \\
\text { No. }\end{array}$ & $\begin{array}{l}\text { Location } \\
\text { of } \\
\text { interview }\end{array}$ & Age & Ethnicity & $\begin{array}{l}\text { Marital } \\
\text { staus }\end{array}$ & G & $\mathbf{P}$ & $\begin{array}{l}\text { Gestation of } \\
\text { previous } \\
\text { preterm birth } \\
\text { or } \\
\text { miscarriage }\end{array}$ & Group & $\begin{array}{l}\text { Having } \\
\text { serial } \\
\text { CL } \\
\text { scans } \\
\text { as } \\
\text { well? }\end{array}$ & $\begin{array}{l}\text { PTB } \\
\text { prophylaxis? }\end{array}$ & $\begin{array}{l}\text { Previous } \\
\text { speculum } \\
\text { exam? }\end{array}$ & $\begin{array}{l}\text { Index of } \\
\text { Multiple } \\
\text { Deprivation } \\
\text { (IMD) } \\
\text { Decile* }\end{array}$ \\
\hline 18 & $\begin{array}{l}\text { Antenatal } \\
\text { ward }\end{array}$ & 34 & $\begin{array}{l}\text { White } \\
\text { British }\end{array}$ & Married & 10 & 3 & $\begin{array}{l}\text { Recurrent 1st } \\
\text { trimester } \\
\text { miscarriages } \\
+23 \text { week } \\
\text { miscarriage } \\
+ \text { three } 33- \\
34 \text { week } \\
\text { deliveries }\end{array}$ & $\begin{array}{l}\text { High } \\
\text { risk }\end{array}$ & yes & $\begin{array}{l}\text { USS } \\
\text { indicated } \\
\text { suture and } \\
\text { progesterone }\end{array}$ & yes & 7 \\
\hline 19 & University & 37 & Libyan & Married & 6 & 3 & $\begin{array}{l}\text { One } 21 \text { week } \\
\text { miscarriage } \\
+ \text { one } 1 \text { st } \\
\text { trimester } \\
\text { miscarriage, } \\
3 \text { term births } \\
\text { since }\end{array}$ & $\begin{array}{l}\text { High } \\
\text { risk }\end{array}$ & no & $\begin{array}{l}\text { elective } \\
\text { cerclage }\end{array}$ & yes & 3 \\
\hline 20 & $\begin{array}{l}\text { Antenatal } \\
\text { ward }\end{array}$ & 36 & $\begin{array}{l}\text { White } \\
\text { British }\end{array}$ & $\begin{array}{l}\text { Co- } \\
\text { habiting }\end{array}$ & 8 & 3 & $\begin{array}{l}30 \text { and } 32 \\
\text { week } \\
\text { deliveries, } \\
\text { term birth } \\
\text { since. }\end{array}$ & $\begin{array}{l}\text { High } \\
\text { risk }\end{array}$ & yes & progesterone & yes & 2 \\
\hline 21 & University & 30 & $\begin{array}{l}\text { White } \\
\text { British }\end{array}$ & Married & 2 & 0 & $\mathrm{n} / \mathrm{a}$ & $\begin{array}{l}\text { Low } \\
\text { risk }\end{array}$ & no & no & yes & 9 \\
\hline
\end{tabular}

Four over-arching themes were actively generated which summarised women's accounts of undergoing EIS and the other screening tests: (i) the physical consequences of testing; (ii) emotional experiences during study visits and pregnancy; (iii) additional determinants of the screening experience and (iv) practical considerations regarding wider use of EIS. An overall synthesis of primary and secondary themes is provided in Table 3 with exemplar quotes to demonstrate each theme. 
Table 3

- Synthesis of Interview Themes

\begin{tabular}{|lll|}
\hline Main Theme & \multicolumn{1}{c}{ Sub-themes } & \\
\hline $\begin{array}{l}\text { 1) Physical } \\
\text { consequences }\end{array}$ & 1) Of EIS & $\begin{array}{l}\text { Unable to feel } \\
\text { measurements }\end{array}$ \\
\hline
\end{tabular}

\section{Exemplar Quote}

"Yes, I don't- when she did the pen thing, I can't remember what it's called (I: The impedance?) Yes. I didn't even feel anything, or notice anything that was happening. It was as if it hadn't happened. But it had been done, because I didn't even notice anything being done. So that was quite good."

Participant 13

(HR, two MTLs, early miscarriage and three term births)

Unusual sensation experienced
"It's like a bit of pressure I guess inside-it's like nothing I have ever felt before. It's kind of inside and up (laughs) but not painful just...just pressure, a strange kind of pressure which is not a normal feeling; you would not normally experience that."

Participant 20

(LR, first pregnancy)

Pain/discomfort/negative descriptors

"...it sort of felt like I was getting an IUD (intrauterine device) put in. There's a little pinch or a poke or something. But I think it's the way, I think she moved it or something. So it wasn't actually the instrument, it may have been the handling of the instrument."

Participant 10

(HR, one PTB, one term birth)

Positive descriptors

"Couldn't really feel much with that to be honest ummm I felt the swabs more and the speculum being placed than the impedance test, it was more like a very gentle pressure and then hearing the beeps so ... yeah it wasn't uncomfortable"

Participant 14

(HR, one PTB)

Post-test symptoms

"Nothing changed. I mean absolutely nothing changed. There was no bleeding, there was no discharge, I didn't feel any aching. Nothing."

Participant 18

(HR, one MTL and early miscarriage, three term births)

2) Of other Speculum screening tests
"I think for me, the speculum is, not painful, but the most uncomfortable part of it."

\section{Participant 11}

(HR, one 23 week delivery and neonatal death)

Swabs

"The swab is the one that's, the swab is actually the one that's uncomfortable... I mean you can feel it, you can sense it... you can actually feel it scraping, even though you know it's a cotton swab and it's just gentle"

\section{Participant 18}

(HR, one MTL and early miscarriage, three term births)

TVUSS
Yes, like I think the cervical scan is gentler than the rest of it, so I think it's more having-and especially I think because I've had a lot of scans where they've used it to look at my ovaries, and they've been quite you know, whereas a cervical scan is much softer than that even, because they literally just want to gently go in and they can see everything. Whereas I'm used to cervical scans where you're really looking for your ovaries and your follicles and stuff. So it's really gentle. It's almost like she only really needed to put a tiny bit of the tip in really, just to see what she needed to see.

Participant 6

(LR, first pregnancy) 


\begin{tabular}{|c|c|c|c|}
\hline Main Theme & Sub-themes & & Exemplar Quote \\
\hline $\begin{array}{l}\text { 2) Emotional } \\
\text { experiences }\end{array}$ & $\begin{array}{l}\text { 1) In relation } \\
\text { to EIS }\end{array}$ & $\begin{array}{l}\text { Uncertainty re: impending } \\
\text { physical experience }\end{array}$ & $\begin{array}{l}\text { "It was definitely far less of a feeling or a pain feeling than I had expected. I } \\
\text { expected to feel more invasive." }\end{array}$ \\
\hline
\end{tabular}

Participant 2

(LR, recurrent first trimester miscarriages, first ongoing pregnancy)

Concerns re: safety of novel test

"I was a little bit, I have to say I was a little bit, you know because it's research and someone's checking, I sort of felt that if you're taking part in something, you can't completely say that there isn't any risks. So that part of the research, I was anxious about that a little bit, but once I'd finished and sort of a couple of hours later, I wasn't feeling any different, I mean it was fine.

...I wasn't worried, but I was a little bit- It's still a risk, it's still, even though you're guaranteed 99\%, there's always 1\% of these going the opposite way."

Participant 7

(LR, one term birth)

2) In relation Impact of visual result of to other CL scan

"If she had just tried to explain that it is short, but seeing it myself on that screening tests screen, it's made me realise that I can't be messing about
home. I've got to listen to what they're telling me to do."

Participant 19

(HR, two PTB and one term birth)

Psychological impact of CL scan results

"It was just really reassuring to know exactly what was happening because you can't feel anything can you with your cervix, so it's impossible to know without the scans."

Participant 11

(HR, one 23 week delivery and neonatal death).

Psychological impact of FFN results

"The first study visit I did have a slight increase in fibronectin result.... which was a surprise and then a worry as well because obviously I didn't expect anything to be picked up on it"

Participant 14

(HR, one PTB)

3) During Fear and anxiety in pregnancy pregnancy

"Yes I think for me, it were like a blessing really, because I was already really in general pregnancy paranoid about just being even pregnant. I think I was really, really scared"

Participant 9

(LR, first pregnancy)

Falling through the gaps of antenatal care

"P: You know if I'd not had all these tests done, I know for a fact l'd be thinking all the time, is that something? Is that something?

I: What would you have done? Who would you have gone to?

P: I don't know. I probably would have just drove myself and my husband crazy I think (both laugh). I went to the doctors originally, and the mid-wife. And I explained to them about my anxiousness, and the fact that I didn't know what had happened last time and how that was making me feel. And I felt that it got dismissed a little bit there."

Participant 5

(HR, one term birth, one PTB)

4) During pregnancy
Emotional burden of previous obstetric trauma
"I never actually think about it, because it's been 5 years now. But you're totally out of control. Like you can't do anything. You can't help your kid, you can't do anything. You just have to like be there and it's just not how life should begin, that stressful you know... I can't even look at pictures of her, because she's so tiny"

Participant 10

(HR, one PTB, one term birth) 


\begin{tabular}{|c|c|c|c|}
\hline \multirow[t]{4}{*}{ Main Theme } & \multicolumn{2}{|l|}{ Sub-themes } & Exemplar Quote \\
\hline & & $\begin{array}{l}\text { Cycle of anxiety in } \\
\text { subsequent pregnancy }\end{array}$ & $\begin{array}{l}\text { "And then the day before I come in, apart from this time and last time, I had } \\
\text { a really sleepless night because I'm thinking what is it going to show? } \\
\text { What's it going to show? And I can find myself just being laid wide awake, } \\
\text { but then once l'd been I can sleep safe and sound again for a couple of } \\
\text { weeks" }\end{array}$ \\
\hline & & & Participant 5 \\
\hline & & & (HR, one term birth, one PTB) \\
\hline \multirow{26}{*}{$\begin{array}{l}\text { 3) Additional } \\
\text { determinants } \\
\text { of screening } \\
\text { experience }\end{array}$} & \multirow{5}{*}{$\begin{array}{l}\text { 1) The } \\
\text { design of } \\
\text { the EIS } \\
\text { probe }\end{array}$} & & "P: I mean it's sort of funny looking. \\
\hline & & & I: What do you mean by that? \\
\hline & & & $\begin{array}{l}\text { P: Well I think because it's long and it's like lights on it, and it makes a } \\
\text { noise... }\end{array}$ \\
\hline & & & Participant 10 \\
\hline & & & (HR, one PTB, one term birth) \\
\hline & \multirow[t]{9}{*}{$\begin{array}{l}\text { 2) } \\
\text { Perspectives } \\
\text { on intimate } \\
\text { examination }\end{array}$} & $\begin{array}{l}\text { The vagina as a protected } \\
\text { space }\end{array}$ & $\begin{array}{l}\text { "A speculum's a bit uncomfy when you're pregnant to kind of open you up a } \\
\text { bit. And I suppose if you don't have to have that done when you're } \\
\text { pregnant... Well you'd prefer not to have the speculum if you don't have to" }\end{array}$ \\
\hline & & & Participant 6 \\
\hline & & & (LR, first pregnancy) \\
\hline & & $\begin{array}{l}\text { Intimate examinations as } \\
\text { normal }\end{array}$ & $\begin{array}{l}\text { "I don't feel it were, like there were no pain at all. It was literally just a bit } \\
\text { uncomfortable. That's all you can, well all I can really say about it, but other } \\
\text { than that because it doesn't hurt, because it's just a normal thing." }\end{array}$ \\
\hline & & & Participant 3 \\
\hline & & & (LR, one term birth) \\
\hline & & $\begin{array}{l}\text { Intimate examinations as } \\
\text { beneficial }\end{array}$ & $\begin{array}{l}\text { "For me, it's ok. It's a little weird, but is not hurting, it's not pain. I know that } \\
\text { it's just for good things. So I'm not worried... Maybe that is uncomfy. But } \\
\text { because it's good reason to do it, because you need to know something, you } \\
\text { just don't mind." }\end{array}$ \\
\hline & & & Participant 1 \\
\hline & & & (LR, one term birth) \\
\hline & \multirow{9}{*}{$\begin{array}{l}\text { 3) Attitudes } \\
\text { to } \\
\text { knowledge } \\
\text { in } \\
\text { pregnancy }\end{array}$} & Pre-existing knowledge of & "so before I had my daughter, I didn't even know you could deliver early" \\
\hline & & & Participant 10 \\
\hline & & & (HR, one preterm birth, one term birth) \\
\hline & & "No-one knew why" & $\begin{array}{l}\text { "I've had a premature baby before, and the reasons for that birth were } \\
\text { unexplained. So going into this pregnancy, I was quite anxious about it } \\
\text { happening again and what may have caused it last time and things like } \\
\text { that... you know if I'd not had all these tests done, I know for a fact I'd be } \\
\text { thinking all the time, is that something? Is that something?" }\end{array}$ \\
\hline & & & Participant 5 \\
\hline & & & (HR, one term birth, one PTB) \\
\hline & & “It's good to know" & $\begin{array}{l}\text { "No I know, that's what my sister says. She's like 'oh I don't even want to } \\
\text { think about it'. I'm like 'yes do, like shit happens, you should know'.. But see } \\
\text { if I'm trying to think like before all this happened, if somebody offered me } \\
\text { this, would I say yes? And I would, yes, I guess I would. Because you know, } \\
\text { more knowledge is better than no knowledge." }\end{array}$ \\
\hline & & & Participant 10 \\
\hline & & & (HR, one PTB, one term birth) \\
\hline & \multirow[t]{3}{*}{$\begin{array}{l}\text { 4) Screening } \\
\text { environment }\end{array}$} & & $\begin{array}{l}\text { "I had a blanket over my legs... and the door was locked, and she locked it } \\
\text { so I could see she had locked it and there was a curtain and everything..." }\end{array}$ \\
\hline & & & Participant 20 \\
\hline & & & (LR, first pregnancy) \\
\hline
\end{tabular}

Page $11 / 22$ 


\begin{tabular}{|c|c|c|c|}
\hline \multirow[t]{2}{*}{ Main Theme } & \multicolumn{2}{|l|}{ Sub-themes } & \multirow{2}{*}{$\begin{array}{l}\text { Exemplar Quote } \\
\text { "She was talking, so she sort of made me feel comfortable, because we } \\
\text { continued talking about something completely different to what we were } \\
\text { doing. So I didn't feel- I think the fact that she was a female made it slightly } \\
\text { better too." }\end{array}$} \\
\hline & $\begin{array}{l}\text { 5) } \\
\text { Interactions } \\
\text { with clinical } \\
\text { staff }\end{array}$ & Gender & \\
\hline & & & Participant 7 \\
\hline & & & (LR, one term birth) \\
\hline & & $\begin{array}{l}\text { Explanation/ } \\
\text { communication }\end{array}$ & $\begin{array}{l}\text { "She was very good at explaining all the way through what she was doing, } \\
\text { what it was going to be like and things. It's a little bit like the dentist we've } \\
\text { got just now, he talks so that you know exactly what he's doing, so you } \\
\text { never are caught unaware like 'what was that?' or you know 'that felt weird" } \\
\text { or whatever, because if you have that kind of dialogue through it then you } \\
\text { know what you're expecting and what's going to happen". }\end{array}$ \\
\hline & & & Participant 12 \\
\hline & & & (LR, one term birth) \\
\hline & & $\begin{array}{l}\text { Bedside manner and } \\
\text { rapport }\end{array}$ & $\begin{array}{l}\text { "I think as the weeks have progressed, I feel that we've got, I feel that we've } \\
\text { built up quite a good rapport between us, and I do trust her. So she when she } \\
\text { said things to me, I've been able to walk out and thing 'well actually she's } \\
\text { told me it's alright, so I've not got to worry about it until next time'. It's very } \\
\text { reassuring. }\end{array}$ \\
\hline & & & Participant 5 \\
\hline & & & (HR, one term birth, one PTB) \\
\hline \multirow[t]{12}{*}{$\begin{array}{l}\text { 4) Practical } \\
\text { considerations } \\
\text { for broader } \\
\text { implementation } \\
\text { of EIS }\end{array}$} & \multirow[t]{3}{*}{$\begin{array}{l}\text { 1) } \\
\text { Information } \\
\text { leaflet }\end{array}$} & & $\begin{array}{l}\text { "Like some of the bits I was like what is that? But most of it.... It was just all } \\
\text { technical, well not technical but like, it were just like, I knew all the ins and } \\
\text { outs of it so it weren't too hard....I would say to mum 'what is that?' 'What's } \\
\text { that one mean?' I can't really remember all of it. I didn't ignore it, I just read a } \\
\text { bit of it." }\end{array}$ \\
\hline & & & Participant 3 \\
\hline & & & (LR, one term birth) \\
\hline & \multirow[t]{3}{*}{$\begin{array}{l}\text { 2) Timing } \\
\text { and } \\
\text { frequency of } \\
\text { screening }\end{array}$} & & $\begin{array}{l}\text { "I think if it was at a time when you were coming to hospital anyway, like the } \\
20 \text { week scan, then I think that would be a really good idea. But like I was } \\
\text { saying earlier, it kind of put me off taking part in the study before I had a } \\
\text { premature labour, just because of work and commitments and thinking 'oh I } \\
\text { need to take more time off'..." }\end{array}$ \\
\hline & & & Participant 11 \\
\hline & & & (HR, one 23 week delivery and neonatal death) \\
\hline & \multirow{6}{*}{$\begin{array}{l}\text { 3) Women's } \\
\text { opinions on } \\
\text { overall } \\
\text { acceptability } \\
\text { for wider } \\
\text { use in } \\
\text { antenatal } \\
\text { care }\end{array}$} & $\begin{array}{l}\text { In favour of universal } \\
\text { screening }\end{array}$ & $\begin{array}{l}\text { "...yes I think everybody should do it. I don't know, sorry. I'm just a survivor of } \\
\text { premature birth so I'm sort of for everything." } \\
\text { Participant } 10 \\
\text { (HR, one PTB, one term birth) }\end{array}$ \\
\hline & & Dependent on risk status & $\begin{array}{l}\text { "P: Whether I'd feel I would need to have it if I've gone through two, you } \\
\text { know if I've had two kids already that haven't had any premature-ness, then I } \\
\text { don't know if I'd feel the need if it was like you can have this or not have it. }\end{array}$ \\
\hline & & & I: If it was an option, you think that you would probably decline? \\
\hline & & & $\begin{array}{l}\text { P: Only in that I wouldn't have the worry if myself to find out whether there } \\
\text { was a risk of being premature. But I wouldn't not have it if it was an offer I } \\
\text { think, because the procedure wasn't anything that you wouldn't just say oh } \\
\text { yes that's fine, I can just have that as well so I know for sure that things are } \\
\text { ok." }\end{array}$ \\
\hline & & & Participant 12 \\
\hline & & & (LR, one term birth) \\
\hline
\end{tabular}




\begin{tabular}{|c|c|c|c|}
\hline Main Theme & Sub-themes & & Exemplar Quote \\
\hline & & \multirow[t]{3}{*}{$\begin{array}{l}\text { Trade-off between burden } \\
\text { of tests and information } \\
\text { gained }\end{array}$} & $\begin{array}{l}\text { "...you'd prefer not to have the speculum if you don't have to. As a routine } \\
\text { measure, it would be, but if it definitely picked up lots of, you know if it was } \\
\text { going to pick up the risk of having a premature labour then yes it was } \\
\text { definitely worth it, because it's nothing compared to that" }\end{array}$ \\
\hline & & & Participant 6 \\
\hline & & & (LR, first pregnancy) \\
\hline
\end{tabular}

\section{Physical consequences of testing}

Women described the physical experience of screening in depth, with respect to both EIS and the other tests. The accounts of EIS were grouped into 5 sub-themes: "unusual" sensations; positive descriptions of measurements; pain/discomfort/negative descriptors; no sensation associated with measurement and post-test symptoms.

\section{Emotional experiences}

Participants also detailed a range of emotions before and after study visits which inevitably shaped their overall perspective on their experiences. Some emotions related to EIS, with specific sub-themes of uncertainty regarding the impending physical experience and concerns regarding the safety of novel tests identified. However, others pertained to the conventional tests and specific sub-themes of general reassurance from screening; the visual impact of the $\mathrm{CL}$ result; and the specific psychological impact of $\mathrm{CL}$ scanning and FFN testing were evident.

\section{Additional determinants of screening experience}

These included the design of the EIS probe, women's pre-existing perspectives on intimate examination and attitudes to knowledge in pregnancy, the screening environment and interaction with clinical staff.

The sub-theme of perspectives on intimate examination incorporated two polarised stances: Some viewed the vagina as a protected space, with resultant caution regarding internal examination in pregnancy; others identified intimate examination as a normal, beneficial, part of pregnancy. Many felt that familiarity with intimate examination increases tolerance.

The 'attitudes to knowledge in pregnancy' subtheme draws together several concepts which all influence women's perspectives on preterm screening, including prior knowledge and understanding of PTB, a lack of explanation for prior PTBs (where relevant) and the perception that knowledge during pregnancy is a good thing, in and of itself.

Women noted that provision of an appropriate, private screening environment positively impacted their experience. Similarly, clear communication and detailed explanation from the operator at all stages of screening was valued, as was continuity of care and the opportunity to build a rapport. Operator gender was also an important factor for several participants.

\section{Practical considerations regarding wider use of EIS}

Some participants (in particular HRW) supported universal screening, whereas others preferred a risk based approach to offering additional tests. Several highlighted the need to balance costs and benefits of screening.

\section{Triangulation}

\section{Anxiety}

It is important to note that whilst assessments of pain and device design were relatively specific to EIS, anxiety ratings related more broadly to the screening package as a whole (and indeed to the pregnancy itself). Triangulation demonstrated general agreement between datasets regarding the reduction in anxiety after screening. However, it also detected context-specific examples of dissonance - notably in one woman who received a false positive fibronectin and another LR woman who felt that study participation had increased her awareness of (and therefore worry about) PTB. Both women qualified this by describing the net reassurance they obtained from participation, even though their anxiety was heightened at specific time-points. For example: 
"It just made me aware of that concern of premature birth that I haven't really considered at all before. But now the tests are complete, I'm really glad I've taken part in them."

Participant 2 (LR, recurrent first trimester miscarriages, first ongoing pregnancy)

A variety of sub-themes were also identified during SSIs which help explain women's anxiety and the emotional impact of the different screening tests.

As women and clinicians were blinded to spectroscopy results, there was no possibility of EIS itself providing direct reassurance about PTB risk. However, one EIS-related explanation for the observed trends was supported by complementary SSI data: namely, some women were anxious about the safety of undergoing a novel test in pregnancy but were reassured when they had no adverse experiences afterwards. This viewpoint was expressed by both HR and LRW. Uncertainty regarding the impending physical experience of EIS (or indeed other unfamiliar tests encountered during screening) similarly was a potential source of increased pre-test anxiety, as illustrated by participants 17 and 9 :

"the only thing I was concerned about or I'd thought about before was actually done was how much am I going to feel is it going to be like an electric shock kind of thing..."

Participant 17 (HR, recurrent first trimester miscarriages, three PTBs, one MTL)

"It wasn't anything invasive or, you know, I think I expected it to be, you know the whole situation to be a bit uncomfortable, but it wasn't."

Participant 9 (LR, first pregnancy)

Triangulation of individual items of the STAI- 6 shows that many of the women's emotional responses to testing were not specific to the EIS procedure (e.g. worry and anxiety related to abnormal tests, pre-test worries due to prior knowledge of PTB, e.g. due to family history). Moreover, the reassurance of receiving normal CL and FFN results contributed significantly to reduced post-test anxiety. When women did have worries resulting from positive test results they often framed this as a good thing (describing knowledge as good, and as a chance for action).

Additionally, the results of quantitative analysis suggested a possible bimodal distribution of pre and post-test STAI-6 scores amongst HRW (Additional file 3). Interview findings were concordant, with a subset of HRW providing detailed accounts of their marked pregnancy-related anxiety. Such emotions were not universally expressed, but when present, were a noticeable focus at interview. A range of complementary subthemes emerged, with HRW discussing reasons for their anxiety (lack of explanation of previous PTBs, the traumatic nature of previous pregnancies, difficulty accessing support from clinicians, fear of recurrent problems), their pattern of emotions (with cyclical anxiety in relation to appointments a strong theme) and their coping mechanisms (seeking information/explanation, developing trust and rapport through relationships with care givers, reframing abnormal test results as positive opportunities for action/preparation). HRW who had experienced later PTBs or positive outcomes following PTB did not typically express such strong emotions at interview. LRW were generally less emphatic in their expressions of anxiety and reassurance, consistent with questionnaire results. However, those who had undergone fertility treatment, experienced early miscarriage or with family history of PTB described higher anxiety. Nulliparity was also a source of worry for several LRW.

\section{Pain}

Pain ratings also showed high concordance with interview data. Scores on both VAS and PPI scales were low, and similarly women made efforts to ensure their descriptions of the physical experience of EIS were not interpreted as pain during the SSIs. Phrases such as "it's not a pain at all" (Participant 5), "it's not painful in any way" (Participant 17) were often used as a prefix or suffix to more detailed descriptions. The qualitative descriptor most commonly used at interview was not included in the fifteen item McGill list: both HR and LRW frequently described a feeling of "pressure". However, this may have been influenced by the real time explanations from the CRF during screening, as illustrated by Participant 3 :

"She said it would be a bit like pressure or something. I think she said pressure, something like that, but it weren't, it were fine"

Participant 3 (LR, one term birth)

The only discordant account noted at interview was that of one HRW (Participant 10), who described a higher degree of discomfort than anyone else ("it felt like it poked, a sort of stabbing poke...", "it sort of felt like I was getting an IUD put in"). Interestingly her score on the VAS was 3 and on the PPI 2 (discomforting) which overall does not appear suggestive of high pain intensity (although her scores did represent the top of the range recorded for HRW). However, she too qualified her description ("But I think it's the way, I think she moved it or something. So it wasn't actually the instrument, it may have been the handling of the instrument"), perhaps suggesting a transient sensation at one reading, rather than a consistent sensation across all six readings at the two study visits.

Page 14/22 
Although items from the affective subscale of the McGill PRI were not commonly selected by questionnaire respondents, complementary themes from the interviews did emerge which detail the interplay between the emotional and physical experience of EIS. These include uncertainty regarding impending physical experience, concerns regarding the safety of a novel test and their perspectives on intimate examination. Women who expressed the opinion that checks and examinations were useful often found the physical experience particularly manageable - for example Participant 1, who recorded scores of 0 on both the VAS and the PPI:

"For me, it's ok. It's a little weird, but is not hurting, it's not pain. I know that it's just for good things. So I'm not worried."

Participant 1 (LR, one term birth)

Similarly, some patients who had reflected upon the safety of EIS as a novel test recorded slightly higher pain scores, e.g. Participant 6 (VAS of 3 and PPI of 1) who stated:

"I know it said that there wasn't any harm with the impedance at all. But it would have been nice to have something in there that showed some evidence for that that backed it up like some statistics or previous pilot that says this has happened."

But also:

"To be honest, I'm not sure, because the speculum was in, and I could feel the speculum, I can't say that I massively felt anything. Maybe a little bit of like a tingle or like you were just doing a swab, just being touched kind of thing really"

Participant 6 (LR, first pregnancy)

This slight conflict between pain score and qualitative account could imply that the emotional impact of EIS influenced women's sensory experiences more than the questionnaire data suggests. Alternatively, despite the questionnaire aiming to establish the specific effects of EIS, her pain score may also reflect the discomfort experienced with speculum examination rather than the CR reading itself.

\section{Device design}

Both methodologies yielded useful information concerning the design of the EIS device. The VAS scores spanned a wide range (from 0-9) although the majority (75\%) of participants scored the probe appearance as non-threatening. The interviews confirmed this diversity of opinion; some women barely remarked upon the probe (indeed two said they couldn't remember what it looked like, whilst another participant referred to "the little pen thing"), whereas others expressed quite negative opinions regarding its appearance (using descriptors such as "bulky", "different", "futuristic", "odd, "intimidating", "space age", "scary", "robot probe"). The reflections of the latter group offer detailed insight into which features they found troublesome, including colour, length, the noise the probe made and its wireless connectivity.

\section{Test acceptability}

Finally, the interviews provided significant complementary information regarding test acceptability. All women rated the procedure as acceptable for use in antenatal care however, this was often context specific. Some strongly supported universal PTB screening (indeed, the highest risk women (with previous extreme or multiple PTBs/late miscarriages) provided the most emphatic support for this); others favoured HR screening only. These contrasting perspectives are illustrated by participants 17 and 2 :

"If they roll this out to people antenatally it would just become normal, as normal as having smear tests, it's a really quick thing that could make such a difference."

Participant 17 (HR, recurrent first trimester miscarriages, three PTBs, one MTL)

"I can imagine that if you weren't having any intervention, it might feel quite, quite a serious thing to undertake..it might feel too much for the ordinary woman who wouldn't expect to have medical intervention as part of a normal pregnancy"

Participant 2 (LR, recurrent first trimester miscarriages, first ongoing pregnancy)

Many factors influenced these positions. Subthemes concerning knowledge in pregnancy and perspectives on intimate examination were particularly evident, as were women's emotional experiences of both EIS and other screening tests. Participants who expressed concern about the safety of EIS and/or internal examination were more cautious about the idea of universal screening, in contrast to those who viewed both knowledge and intimate examination as beneficial who gained considerable reassurance from study tests. No women expressed reservations about the use of EIS in HRW - even those who had concerns about examination or EIS safety. HRW were frequently described as having most to gain from screening, which tipped the balance of test burden and benefit:

Page $15 / 22$ 
"You have to think about the costs and the benefits don't you?... I think for cases like mine where I have had a premature birth, then I think it would be very useful, if anything its reassurance for parents that things are being monitored"

(Participant 14, HR, one PTB)

Thus overall, both datasets drew consistent conclusions regarding acceptability for use in HRW, whereas women's qualitative accounts reveal some dissonance with respect to LR screening.

\section{Discussion}

This study used a mixed-methods, parallel convergent approach to comprehensively evaluate women's experiences of undergoing cervical EIS measurements as part of a PTB screening package. It is the first study to assess the acceptability of EIS and also contributes to the concise body of qualitative evidence regarding PTB screening in general. All participants deemed cervical EIS acceptable for use in antenatal care. It is encouraging to compare the binary rating of EIS acceptability with prior studies of PTB screening - these yielded similarly positive acceptability ratings for both $\mathrm{CL}$ scanning and FFN measurement by $\geq 90 \%$ of women ${ }^{17,18}$. EIS was well tolerated (as evidenced by low pain scores and generally concordant SSI accounts). These findings compare favourably to existing data on pain experienced during CL screening (with mean VAS pain scores of 0.5 and 2.4 reported by Heath et al. ${ }^{16}$ and Cicero et al. ${ }^{15}$ respectively, and no or mild pain during TVUSS reported by the majority of participants in studies by Clement et al. ${ }^{17}$ and Romero et al. ${ }^{19}$ ). They provide useful information with which to counsel patients undergoing EIS measurements in future and may help address one of the potential sources of anxiety associated with screening, namely uncertainty about the impending physical experience of a novel test.

Interpretation of the data regarding anxiety is complex. Women's emotional state varied according to risk status, prior experiences, the timing of assessment and their perspectives on intimate examination, novel tests and pregnancy in general. Overall, undergoing screening was associated with a reduction in anxiety and many women with high anxiety levels were particularly emphatic in their appreciation of the reassurance gained through tests and monitoring. For HRW especially, comfort was not gained by the tests alone, but also through detailed explanations, regular attendance and the opportunity to build a rapport with care-givers. There is commonality between these SSI themes and preceding work: O'Brien et $a .^{22}$ have previously noted the importance of the relationship between HRW and the PTB clinic team, and the role frequent checks play in breaking HR pregnancies down into manageable chunks. In both HR asymptomatic ${ }^{22,26}$ and symptomatic women ${ }^{23,24}$, prior studies have demonstrated comparably favourable views of increased surveillance and information provision in pregnancy to those expressed by our cohort.

The existing literature assessing anxiety during PTB screening is heterogeneous. Two studies have utilised the STAI-6 to evaluate the effect of CL scans ${ }^{17}$ and FFN swabs ${ }^{20}$ on maternal anxiety. However, they performed assessments at differing time-points and used single predictors in isolation, making direct comparison difficult. Nevertheless, the results from our cohort were broadly in keeping with those of Clement et al. ${ }^{17}$, who noted significant reduction in worry about PTB after CL scanning. It is notable that women with a short CL were excluded from recruitment, thus they are likely to have over-estimated the reassurance provided by CL screening. In contrast, Shennan et al. ${ }^{20}$ included women with both positive and negative test results in their assessment of FFN. Their finding of significantly increased anxiety in HR vs. LRW mirrors the trend reported in our cohort. Similarly, our isolated observation of increased anxiety post-screening in one LR participant with positive test results is in keeping with their observation that positive FFN swabs increase maternal anxiety. However, not every woman in our study with a short cervix or positive swab demonstrated an increased post-test STAI-6. It is plausible that undergoing more than one predictive test enabled women to reframe their results to mitigate against anxiety (e.g. by focusing on a normal CL if FFN was positive or, if both tests were abnormal, by reframing this knowledge as a positive opportunity for action).Therefore, detailed explanation is a vital element of PTB screening; Both risk groups in our cohort valued this, but it may not always occur in general clinical practice - Carlisle et a/ noted a lack of understanding of PTB tests in symptomatic women, highlighting the need for clear communication when tests are used outwith a PTB clinic environment ${ }^{25}$.

The experience of Participant 2 (the LR woman with heightened awareness of and worry about, PTB following recruitment) emphasizes the need for some caution when contemplating wider use of PTB screening. The advantages of awareness of PTB (increased knowledge of symptoms; empowerment to seek assessment and explanation; greater potential for mitigating/preparatory treatment) must be weighed against the potential disadvantages (e.g. provocation of intense or intrusive worry or anxiety which in itself might have physiological sequelae). The provision of contextual information (e.g. rates of all/very PTBs, management pathways for screen positive women) may help frame women's risk perception, and explanation of how and where to seek help for concerning symptoms is essential. Overall, in this cohort no participant described marked adverse sequelae following screening, whereas HR women often gave vivid accounts of the shock and unpreparedness they felt during index PTBs. It is thus difficult to ascertain the net emotional impact of screening low risk women, but this certainly should be considered in the design and evaluation of potential screening programs. 
Although the design of the EIS probe was generally deemed satisfactory by study participants, the relatively wide range of scores yielded by the questionnaire suggested some diversity of opinion. The SSI data was therefore particularly useful with respect to this element of test acceptability and provided valuable insight into the specific aspects which some women found troublesome. Utilising this information to inform the design of future EIS devices will optimise the testing procedure for broader clinical use. Despite the consensus on EIS acceptability, women had varied opinions on routine screening. No previous qualitative studies have examined women's perspectives on who should be offered PTB screening, thus these findings provide an early insight into the views of a subset of both low and high-risk women.

This study is not without limitations. The sample size for the quantitative survey is modest and it is possible that more marked differences between risk groups would be observed within a larger cohort. In addition, the views reported here represent those who agreed to participate in the original clinical trial. Women declining recruitment could obviously not provide accounts of the screening tests but their views regarding EIS, PTB screening in general and their reasons for refusal may have provided useful information for future clinical policy and practice. Future work should aim to address this knowledge deficit by assessing the opinions of women who decline PTB screening. Whilst effort was made to capture the views of a diverse group of women, the subgroup who participated in the qualitative interviews was predominantly White British. Black and South Asian subgroups were relatively under-represented and, given their particular vulnerability to preterm birth, ongoing work should explicitly seek to clarify their perspectives on the acceptability of EIS. The exclusion of non-English speakers also limits the generalizability of our findings. Resource limitations impacted our ability to adapt study information, instruments and analytic techniques for application to a multilingual population, but we acknowledge the reporting gap this creates and would again to explicitly seek to address this in future work. Nevertheless, this is the first report on the acceptability of cervical EIS and, to our knowledge, the first study employing mixed methods to evaluate women's experiences of PTB screening. Furthermore, prior qualitative work has focused on HR and symptomatic women - the inclusion of LRW in this study provides new insight regarding the tolerability and acceptance of PTB screening in a broader population of pregnant women.

\section{Conclusions}

EIS is an acceptable test to both high and low risk women. The physical experience of undergoing measurements was well tolerated by both groups. The emotional experience of testing was complex and influenced by many factors, some of which were unrelated to EIS measurement itself and stemmed from women's previous pregnancy experiences, pre-existing attitudes to pelvic examinations and medical intervention, as well as their desire for information about their pregnancies. A theme common to many participants was that EIS acceptability was positively influenced by existing rapport between the operator and the woman. Gaining awareness of the way that these and other factors influence women's experience of PTB screening will enable us to develop screening programmes which are acceptable to as many women as possible. This in turn will maximise the effectiveness of any future screening programme.

\section{Abbreviations}

\section{EIS}

Electrical impedance spectroscopy

STAI-6

Six question short form of Spielberger State Trait Anxiety Inventory

PTB

Preterm birth

TVUSS

Transvaginal ultrasound scan

CL

Cervical length

FFN

Fetal fibronectin

QUiPP

Quantitative Instrument for the Prediction of Preterm Birth

LRW

Low-risk women

HRW

High-risk women

VAS

Visual analogue scale

PPI

Present pain intensity

PRI 
Pain rating index

TA

Thematic analysis

\section{Declarations}

Ethics approval and consent to participate - Ethical approval for this study was provided by the Yorkshire and Humber National Research Service Ethics Committee (13/YH/0167) and informed consent gained for all study participants. All procedures performed were in accordance with the ethical standards of the Regional Ethics Committee and with the Helsinki declaration, as per Good Clinical Practice guidance.

Consent for publication - Written informed consent for publication was obtained from all study participants at the time of recruitment.

Availability of data and materials - The dataset used for the quantitative analysis of the acceptability questionnaires is available in additional file 4. Patient consent to share full transcripts of the semi-structured interviews was not obtained during recruitment and complete anonymisation is not feasible as the transcripts include discussion, for example, of prior obstetric history. Therefore, this dataset is not publicly shared but further detail is available from the corresponding author on reasonable request.

Competing interests - VS, none; GJ, none; SS, none; DA, none.

Funding - This study was funded by a grant from the Medical Research Council DPFS Scheme (MR/J005622/1).

Authors' Contributions - DA was Principal Investigator for the whole study and conceived the qualitative work, overseeing study design, analysis and manuscript revision. SS recruited patients alongside VS, conducted the semi-structured interviews and contributed to the thematic analysis of the SSIs. VS performed all main study visits, recruited patients to the qualitative study, analysed the quantitative and qualitative acceptability data and drafted and revised the manuscript. GJ supervised the study design and analysis, advised on interpretation of the findings and critically revised the manuscript. All authors read and approved the final manuscript.

Acknowledgements - The authors would like to thank the women who generously gave up their time to participate in the study. We would also like to acknowledge the staff in the Fetal Medicine Unit in the Jessop Wing who assisted with the conduct of the main clinical study; the research project management team (particularly the Clinical Engineering team who provided ongoing support in maintaining the EIS device for the main study visits); the members of the Jessop Wing Preterm Birth Public and Patient Involvement Panel who provided input throughout the study and the Medical Research Council for their funding.

\section{References}

1. Liu L, Oza S, Hogan D, et al. Global, regional, and national causes of under-5 mortality in 2000-15: an updated systematic analysis with implications for the Sustainable Development Goals. Lancet. Dec 17 2016;388(10063):3027-3035. doi:10.1016/s0140-6736(16)31593-8

2. Marlow N, Bennett C, Draper ES, Hennessy EM, Morgan AS, Costeloe KL. Perinatal outcomes for extremely preterm babies in relation to place of birth in England: the EPICure 2 study. Arch Dis Child Fetal Neonatal Ed. May 2014;99(3):F181-8. doi:10.1136/archdischild-2013-305555

3. NHS England. Saving Babies' Lives Version Two. A care bundle for reducing perinatal mortality. Accessed 08/09/2019, 2019. https://www.england.nhs.uk/wp-content/uploads/2019/07/saving-babies-lives-care-bundle-version-two-v5.pdf

4. World Health Organisation. Born Too Soon. The Global Action Report on Preterm Birth. WHO. Accessed 10/11/19, 2019. https://www.who.int/pmnch/media/news/2012/201204_borntoosoon-report.pdf

5. Romero R, Espinoza J, Kusanovic JP, et al. The preterm parturition syndrome. BJOG. Dec 2006;113 Suppl 3:17-42. doi:10.1111/j.14710528.2006.01120.x

6. National Institute for Health and Care Excellence. Preterm Labour and Birth. London: National Institute for Health and Care Excellence; 2015. Available from: https://www.nice.org.uk/guidance/ng25/resources/preterm-labour-and-birth-pdf-18373335766457.

7. Esplin MS, Elovitz MA, lams JD, et al. Predictive Accuracy of Serial Transvaginal Cervical Lengths and Quantitative Vaginal Fetal Fibronectin Levels for Spontaneous Preterm Birth Among Nulliparous Women. JAMA. Mar 14 2017;317(10):1047-1056. doi:10.1001/jama.2017.1373

8. Jwala S, Tran TL, Terenna C, et al. Evaluation of additive effect of quantitative fetal fibronectin to cervical length for prediction of spontaneous preterm birth among asymptomatic low-risk women. Acta Obstet Gynecol Scand. Aug 2016;95(8):948-55. doi:10.1111/aogs.12907 
9. Brown BH, Tidy JA, Boston K, Blackett AD, Smallwood RH, Sharp F. Relation between tissue structure and imposed electrical current flow in cervical neoplasia. Lancet. 2000;355(9207):892-5.

10. Tidy JA, Brown BH, Healey TJ, et al. Accuracy of detection of high-grade cervical intraepithelial neoplasia using electrical impedance spectroscopy with colposcopy. BJOG. 2013;120(4):400-10; discussion 410-1. doi:10.1111/1471-0528.12096

11. Murdoch $\mathrm{C}$, Brown $\mathrm{BH}$, Hearnden V, et al. Use of electrical impedance spectroscopy to detect malignant and potentially malignant oral lesions. Int J Nanomedicine. 2014;9:4521-32. doi:10.2147/ijn.s64087

12. Braun RP, Mangana J, Goldinger S, French L, Dummer R, Marghoob AA. Electrical Impedance Spectroscopy in Skin Cancer Diagnosis. Dermatol Clin. Oct 2017;35(4):489-493. doi:10.1016/j.det.2017.06.009

13. Anumba DOC, Stern V, Healey JT, Dixon S, Brown BH. Value of cervical electrical impedance spectroscopy to predict spontaneous preterm delivery in asymptomatic women: the ECCLIPPx prospective cohort study. Ultrasound Obstet Gynecol. 2021 Aug;58(2):293-302. doi: 10.1002/uog.22180.

14. Stern V, Anumba D. Potential incorporation of novel cervical impedance spectroscopy assessment into existing clinical algorithms for predicting preterm birth. Eur J Obstet Gynecol Reprod Biol. 2021;256:523-524. doi:10.1016/j.ejogrb.2020.11.019

15. Cicero S, Skentou C, Souka A, To MS, Nicolaides KH. Cervical length at 22-24 weeks of gestation: comparison of transvaginal and transperineal-translabial ultrasonography. Ultrasound Obstet Gynecol. 2001;17(4):335-40. doi:10.1046/j.1469-0705.2001.00345.x

16. Heath VC, Southall TR, Souka AP, Novakov A, Nicolaides KH. Cervical length at 23 weeks of gestation: relation to demographic characteristics and previous obstetric history. Ultrasound Obstet Gynecol.1998;12(5):304-11. doi:10.1046/j.1469-0705.1998.12050304.x

17. Clement S, Candy B, Heath V, To M, Nicolaides KH. Transvaginal ultrasound in pregnancy: its acceptability to women and maternal psychological morbidity. Ultrasound Obstet Gynecol. 2003;22(5):508-14. doi:10.1002/uog.893

18. Carlisle N, Carter J, Radford S, Shennan A. Women's experiences of tests and procedures carried out at a preterm birth surveillance clinic. Br J Midwifery. Jan 2018;26(1):31-34. doi:10.12968/bjom.2018.26.1.31

19. Romero ST, Holmgren CC, Feltovich H, Porter TF, Esplin MS. Cervical length screening: a randomized trial assessing the impact on visit length and patient attitudes. J Ultrasound Med. 2014;33(12):2159-63. doi:10.7863/ultra.33.12.2159

20. Shennan A, Jones G, Hawken J, et al. Fetal fibronectin test predicts delivery before 30 weeks of gestation in high risk women, but increases anxiety. BJOG. 2005;112(3):293-8. doi:10.1111/j.1471-0528.2004.00420.x

21. Carlisle N, Watson HA, Seed PT, et al. Impact of a medical mobile phone app (QUiPP) for predicting preterm birth on the anxiety and decisional conflicts faced by women in threatened preterm labour. Midwifery. 2021;92 doi:10.1016/j.midw.2020.10286422

22. O'Brien ET, Quenby S, Lavender T. Women's views of high risk pregnancy under threat of preterm birth. Sex Reprod Healthc. 2010;1(3):7984. doi:10.1016/j.srhc.2010.05.001

23. Carter J, Tribe RM, Shennan AH, Sandall J. Threatened preterm labour: Women's experiences of risk and care management: A qualitative study. Midwifery. 2018;64:85-92. doi:10.1016/j.midw.2018.06.001

24. Peterson WE, Sprague AE, Reszel J, et al. Women's perspectives of the fetal fibronectin testing process: a qualitative descriptive study. BMC Pregnancy Childbirth. 2014;14:190. doi:10.1186/1471-2393-14-190

25. Carlisle N, Watson HA, Kuhrt K, et al. Ten women's decision-making experiences in threatened preterm labour: Qualitative findings from the EQUIPTT trial. Sex Reprod Healthc. 2021/09/01/ 2021;29:100611. doi:https://doi.org/10.1016/j.srhc.2021.100611

26. White H, Morton VH, Stock SJ, Lavender T. Preterm labour decision-making and experiences of care for women and clinicians (QUIDS Qualitative): A qualitative exploration. Sex Reprod Healthc. 2019 Oct;21:95-101. doi: 10.1016/j.srhc.2019.06.005.

27. O'Cathain A, Murphy E, Nicholl J. Three techniques for integrating data in mixed methods studies. BMJ. Sep 17 2010;341:c4587. doi:10.1136/bmj.c4587

28. Bryman A. Mixed methods research: combining quantitative and qualitative research. Social Research Methods. 5th ed. Oxford University Press; 2016. 
29. Marteau TM, Bekker H. The development of a six-item short-form of the state scale of the Spielberger State-Trait Anxiety Inventory (STAl). Br J Clin Psychol. Sep 1992;31 (Pt 3):301-6.

30. Bayrampour H, McDonald S, Fung T, Tough S. Reliability and validity of three shortened versions of the State Anxiety Inventory scale during the perinatal period. J Psychosom Obstet Gynaecol. 2014 Sep;35(3):101-7. doi: 10.3109/0167482X.2014.950218.

31. Lilliecreutz C, Larén J, Sydsjö G, Josefsson A. Effect of maternal stress during pregnancy on the risk for preterm birth. BMC Pregnancy Childbirth. 2016 Jan 15;16:5. doi: 10.1186/s12884-015-0775-x.

32. Melzack R. The short-form McGill Pain Questionnaire. Pain. Aug 1987;30(2):191-7. doi:10.1016/0304-3959(87)91074-8

33. Gallagher EJ, Bijur PE, Latimer C, Silver W. Reliability and validity of a visual analog scale for acute abdominal pain in the ED. Am J Emerg Med. 2002 Jul;20(4):287-90. doi: 10.1053/ajem.2002.33778.

34. Hawker GA, Mian S, Kendzerska T, French M. Measures of adult pain: Visual Analog Scale for Pain (VAS Pain), Numeric Rating Scale for Pain (NRS Pain), McGill Pain Questionnaire (MPQ), Short-Form McGill Pain Questionnaire (SF-MPQ), Chronic Pain Grade Scale (CPGS), Short Form-36 Bodily Pain Scale (SF-36 BPS), and Measure of Intermittent and Constant Osteoarthritis Pain (ICOAP). Arthritis Care Res (Hoboken). 2011 Nov;63 Suppl 11:S240-52. doi: 10.1002/acr.20543.

35. Luria RE. The validity and reliability of the visual analogue mood scale. J Psychiatr Res. 1975 Apr;12(1):51-7. doi: 10.1016/00223956(75)90020-5.

36. Aitken RC. Measurement of feelings using visual analogue scales. Proc R Soc Med. 1969;62(10):989-993.

37. Bijlenga D, Birnie E, Bonsel GJ. Feasibility, reliability, and validity of three health-state valuation methods using multiple-outcome vignettes on moderate-risk pregnancy at term. Value Health. 2009 Jul-Aug;12(5):821-7. doi: 10.1111/j.1524-4733.2009.00503.x.

38. Morgan DL. Pragmatism as a Paradigm for Social Research. Qualitative Inquiry. 2014-02-03 2014;20:1045-53.

doi:10.1177_1077800413513733

39. Kaushik V, Walsh CA. Pragmatism as a Research Paradigm and Its Implications for Social Work Research. Social Sciences. 2019-09-06 2019;8(9):255.doi:10.3390/socsci8090255

40. Braun V, Clarke V. Using thematic analysis in psychology. Qual Res Psychol. 2006;3(2):77-101.

41. Farmer T, Robinson K, Elliott SJ, Eyles J. Developing and Implementing a Triangulation Protocol for Qualitative Health Research: Qual Health Res.2016;16(3):377-94. doi:10.1177_1049732305285708

42. Julian LJ. Measures of anxiety: State-Trait Anxiety Inventory (STAI), Beck Anxiety Inventory (BAI), and Hospital Anxiety and Depression Scale-Anxiety (HADS-A). Arthritis Care Res (Hoboken). 2011;63 Suppl 11:S467-72. doi:10.1002/acr.20561

\section{Figures}




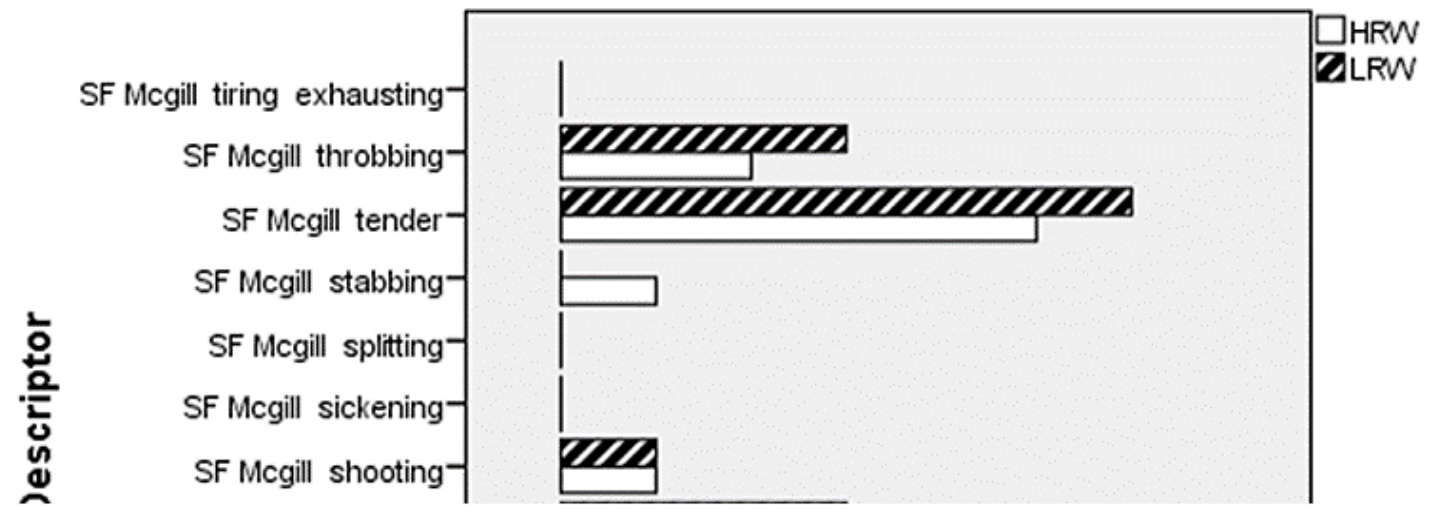

Figure 1

Differences in Qualitative Descriptor Intensity Rating (SF-McGill) Between Study Groups
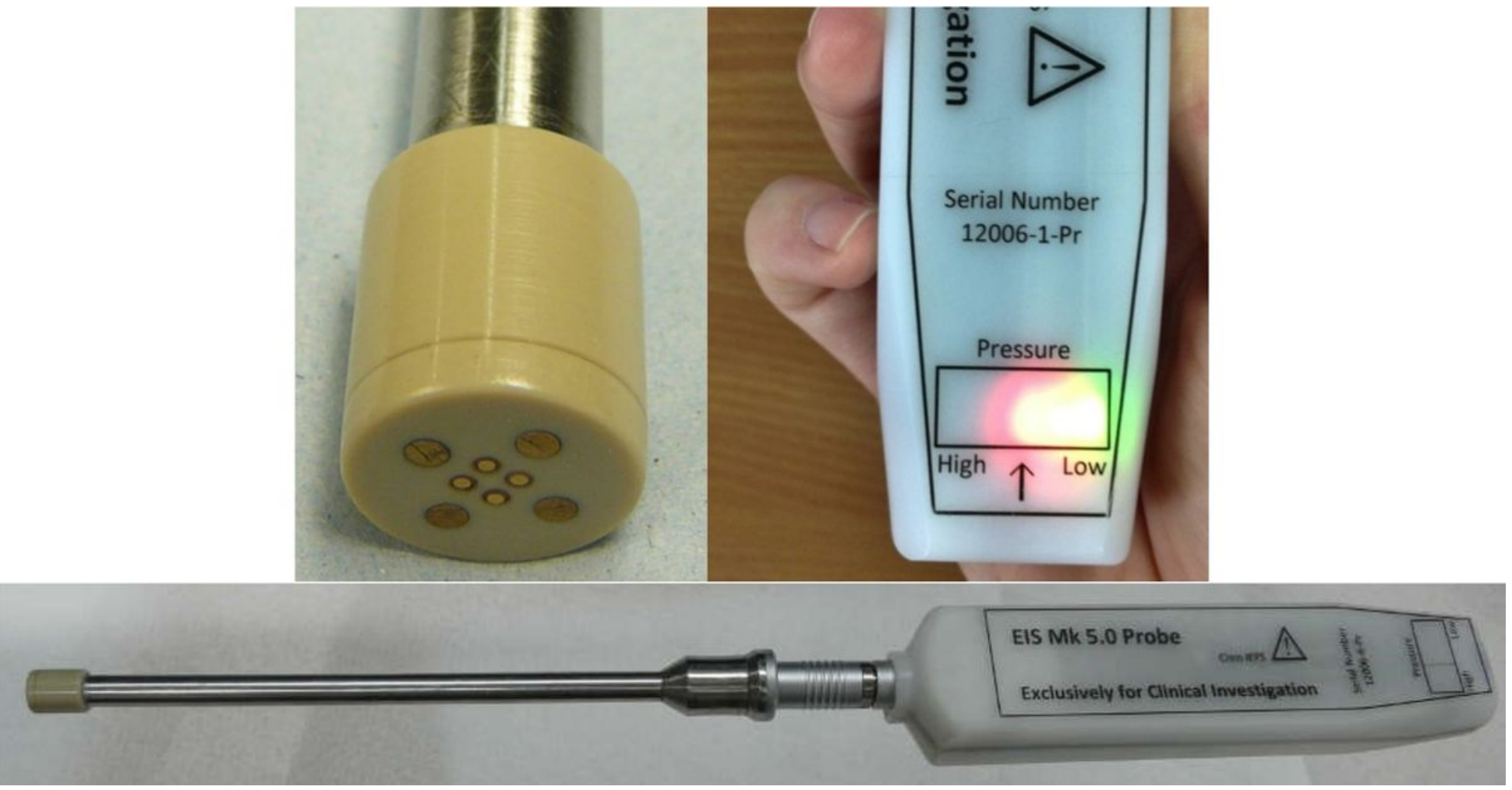

Figure 2 
Appearance of ElS Probe (Sheffield Mark V)

\section{Supplementary Files}

This is a list of supplementary files associated with this preprint. Click to download.

- Additionalfile1.docx

- Additionalfile2.docx

- Additionalfile3.docx

- Additionalfile4.xlsx 